\title{
Evaluation of the association of $C 5$ with neovascular age-related macular degeneration and polypoidal choroidal vasculopathy
}

Ke Liu', Li Ma ${ }^{1}$, Timothy Y. Y. Lai', Marten E. Brelen ${ }^{1,2}$, Pancy O. S. Tam ${ }^{1}$ Clement C. Tham ${ }^{1}$, Chi Pui Pang ${ }^{1}$ and Li Jia Chen ${ }^{1,2^{*}}$

\begin{abstract}
Background: Neovascular age-related macular degeneration (AMD) and polypoidal choroidal vasculopathy (PCV) are sight-threatening maculopathies with both environmental and genetic risk factors. We have previously shown relative risks posed by genes of the complement pathways to neovascular AMD and PCV.

Methods: In this study, we investigated the haplotype-tagging single nucleotide polymorphisms (SNPs) in the complement component 5 (C5) gene in 708 unrelated Chinese individuals: 200 neovascular AMD patients, 233 PCV patients and 275 controls. Six tagging SNPs in C5 were genotyped. Univariate single SNP association analysis, haplotype-based association analysis and gene-gene interaction analysis between C5 and other AMD-associated genes were performed.

Results: The results revealed none of the six tagging SNPs of the C5 gene had a significant association with neovascular AMD or PCV $(P>0.05)$. We also found insignificant haplotype-based association, and no significant SNPSNP interaction between C5 and other genes (including C2-CFB-RDBP-SKIV2L, SERPING1, CETP, ABCG1, PGF, ANGPT2, CFH and HTRA1) for neovascular AMD and PCV.

Conclusions: This study showed no statistical significance in the genetic association of C5 with neovascular AMD or PCV in a Hong Kong Chinese population. Further studies in large samples from different populations are warranted to elucidate the role of $C 5$ in the genetic susceptibility of AMD and PCV.
\end{abstract}

Keywords: Age-related macular degeneration, Polypoidal choroidal vasculopathy, Complete component 5, C5, Genetic association, Single-nucleotide polymorphism

\section{Background}

Neovascular age-related macular degeneration (AMD), characterized by choroidal neovascularization (CNV) at the macular region, is a leading cause of irreversible blindness among the elderly in developed countries [1]. The proportion of neovascular AMD in advanced AMD is higher in Asians than in Caucasians [2]. In the Chinese population it is the major AMD subtype that leads

\footnotetext{
* Correspondence: lijia_chen@cuhk.edu.hk

${ }^{1}$ Department of Ophthalmology and Visual Sciences, The Chinese University of Hong Kong, Hong Kong, China

${ }^{2}$ Department of Ophthalmology and Visual Sciences, Prince of Wales Hospital, Hong Kong, China
}

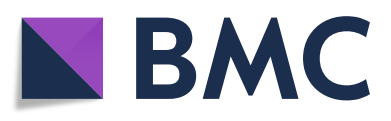

(c) The Author(s). 2019 Open Access This article is distributed under the terms of the Creative Commons Attribution 4.0 International License (http://creativecommons.org/licenses/by/4.0/), which permits unrestricted use, distribution, and reproduction in any medium, provided you give appropriate credit to the original author(s) and the source, provide a link to the Creative Commons license, and indicate if changes were made. The Creative Commons Public Domain Dedication waiver (http://creativecommons.org/publicdomain/zero/1.0/) applies to the data made available in this article, unless otherwise stated. thy $(\mathrm{PCV})$, with characteristic inner choroidal vascular networks ending in polypoidal lesions, is also a sightthreatening maculopathy. PCV belongs to a spectrum of conditions known as pachychoroid, characterized by choroidal thickening that includes central serous chorioretinopathy and PCV $[4,5]$. PCV has been considered as a subtype of neovascular AMD since PCV has overlapping clinical features with neovascular AMD, such as retinal pigmented epithelium (RPE) detachment, submacular hemorrhage, fluid and exudates [6, 7]. However, significant differences between neovascular AMD and PCV have also been observed in epidemiology, clinical 
course and response to treatment $[1,8-10]$. The incidence of PCV in the overall neovascular AMD patients was reportedly about 24.5 to $54.7 \%$ in Asians [1, 11-13], comparing to approximately $8.7 \%$ in Caucasians $[13,14]$. In treatment, neovascular AMD responds well to antivascular endothelial growth factor (anti-VEGF) monotherapy, whilst PCV usually requires combined antiVEGF and photodynamic therapy [13]. The plasma inflammaging profiles are also different between patients with PCV and neovascular AMD [15]. Therefore, whether PCV is a subtype of AMD or a different disease category remains an open question that needs more profound review and investigation.

Both neovascular AMD and PCV are multifactorial in etiology, resulting from the interactions of aging, genetic and environmental factors. In the past decade, molecular genetic studies, including candidate gene analysis, genome-wide association studies (GWAS), and exomewide association studies (EWAS), have identified singlenucleotide polymorphisms (SNPs) in over 30 genes that are associated with AMD [16-22]. Among them, the complement factor $H$ (CFH) gene and the ARMS2/ HTRA1 locus were the most strongly associated with AMD [16, 17, 23, 24] and PCV [25] in different populations, although SNPs at the ARMS2/HTRA1 locus had stronger effect sizes in neovascular AMD than in PCV [25]. In contrast, an exome-wide association study identified a rare variant (p.Lys329Arg) in the FGD6 gene to be significantly associated with PCV but not with neovascular AMD [26]. These findings suggested some genetic components of neovascular AMD and PCV are different. Therefore, studies involving both neovascular AMD and PCV will help to decipher the genetic similarities and differences between these two clinical phenotypes. Moreover, epigenetics may also be involved in the development of AMD and PCV [27, 28]. Therefore, detailed assessment of the environmental and constitutional factors followed by interaction analysis with genetic factors would help to better assess the risk of developing AMD and PCV.

Association of the $C F H$ gene with AMD has revealed the involvement of genes in the complement pathway in AMD pathogenesis. Subsequently, candidate gene association analyses suggested that genes encoding other complement components were also associated with AMD and/or PCV, including complement component 2 (C2), complement factor $B(C F B)$, complement component 3 (C3), and complement factor I (CFI) [29-32]. The complement system is part of the innate immune system in human and plays a role in clearing pathogens from organisms and eliminating immune complex. Essentially three pathways activate the complement system: the classical, alternative and lectin pathways. Regardless of their initiation points, these three pathways merge at the activation of $\mathrm{C} 3$ by a $\mathrm{C} 3$ convertase, which cleaves $\mathrm{C} 3$ into $\mathrm{C} 3 \mathrm{a}$ and $\mathrm{C} 3 \mathrm{~b}$. Binding of $\mathrm{C} 3 \mathrm{~b}$ and a C3 convertase forms a C5 convertase, cleaving $\mathrm{C} 5$ into $\mathrm{C} 5 \mathrm{a}$ and $\mathrm{C} 5 \mathrm{~b}$. The $\mathrm{C} 5$ protein plays a role in the pathogenesis of AMD as evident by its presence in drusen $[33,34]$ and the elevation of $\mathrm{C} 5 \mathrm{a}$ in peripheral blood of AMD patients [35, 36]. Secretion of the angiogenic factor vascular endothelial growth factor from retinal pigment epithelium cells was up-regulated by C5a both in vitro and in vivo [37, 38]. C3a and C5a in the RPE and choroid was upregulated in laser-induced $\mathrm{CNV}$ mice models, whilst genetic ablation of $\mathrm{C} 3 \mathrm{a}$ and $\mathrm{C} 5 \mathrm{a}$ receptors caused reduction of laser-induced CNV in mice models [37]. All these evidences suggested that C5a may be involved in the development of $\mathrm{CNV}$, which is the hallmark of neovascular AMD.

So far, the role of $C 5$ as an AMD-associated gene remains uncertain. No significant association between $C 5$ and advanced AMD was identified in Caucasians in the studies of Yates et al. and Maller et al. [30, 31], while a significant association was identified in another Caucasian cohort [39]. In contrast, the association between $C 5$ and PCV has not been reported in the literature. We have previously shown in ethnic Chinese the genetic susceptibility of neovascular AMD and PCV with genes in the complement pathways, CFH, SERPING1, C2, and C3 [23, 40-42]. Herein we performed a haplotype-tagging SNP-based association analysis to evaluate the association of $C 5$ with neovascular AMD and PCV in Chinese.

\section{Methods}

\section{Study participants}

The study protocol was approved by the Ethics Committee on Human Research, The Chinese University of Hong Kong. The study procedures followed the tenets of the Declaration of Helsinki. All study subjects provided written informed consent.

This study involved a total of 708 unrelated Chinese study subjects consisting of 200 neovascular AMD patients, $233 \mathrm{PCV}$ patients and 275 healthy controls. They were recruited from the Hong Kong Eye Hospital and the Eye Centre of the Prince of Wales Hospital, Hong Kong. The study subjects had been involved and described in our previous reports [19, 20, 40-44]. In brief, all patients underwent complete ophthalmic examinations, including visual acuity, ocular tonometry, slit-lamp biomicroscopy, ophthalmoscopy, fundus photography, fluorescein angiography, and indocyanine green angiography (ICGA). All AMD patients had been diagnosed as having neovascular AMD in at least one eye. PCV was diagnosed by characteristic polypoidal lesions from the choroid on ICGA. Patients with presence of both CNV and PCV lesions in the same or fellow eye were excluded. Unrelated control subjects were recruited from 
people who attended the clinic for eye examinations and aged older than 60 years with no signs of AMD, PCV or other eye diseases, except mild senile cataracts and mild refractive errors. Demographic information has been summarized in Table 1.

\section{SNP selection and genotyping}

Six SNPs (rs2269066, rs17611, rs1548782, rs10985126, rs12237774 and rs1017119) were selected to cover and tag the entire C5 gene. SNP data for Han Chinese in Beijing population (CHB) was obtained from the International HapMap Project (http://hapmap.ncbi.nlm.nih. gov/, HapMap Genome Browser release \#27). The tagging SNPs were selected by a pairwise method with a minor allele frequency cutoff of 0.1 and $r^{2}$ cutoff of 0.8 , adopting a functional ranking system wherein nonsynonymous SNPs were selected preferentially, followed by synonymous SNPs, SNPs in $5^{\prime}$ untranslated regions, SNPs in 3' untranslated regions, and SNPs in introns.

Genomic DNA was extracted from peripheral blood using a DNA extraction kit (Qiagen QIAamp DNA Blood Mini kit, Qiagen, Hilden, Germany) according to the manufacturer's protocol. The six tagging SNPs were genotyped using TaqMan genotyping assays (Applied Biosystems [ABI], Foster City, CA) on a Roche LightCycler 480 Real-Time PCR System (Roche, Switzerland) according to the manufacturer's instructions.

\section{Statistical analysis}

Age and gender difference between cases and controls were assessed using the independent $t$-test and the chisquare test, respectively, with SPSS software version 20.0 (SPSS Inc., Chicago, IL). Hardy-Weinberg Equilibrium (HWE) of individual SNPs were tested using PLINK (v1.07, http://zzz.bwh.harvard.edu/plink). Allelic and genotypic association of all SNPs with neovascular AMD and PCV were evaluated by the chi-square test or Fisher's exact test, and age and gender were adjusted by logistic regression in PLINK. The wild type allele was taken as reference for estimating odds ratio (OR) and 95\% confidence interval (CI). Haplotype association analysis was performed using the confidence interval method in Haploview (v4.2, http://www.broad.mit.edu/ $\mathrm{mpg} /$ haploview).
As the proteins encoded by $C 5$ and $C 3$ interact biologically in the complement pathway, pairwise interaction analysis between the tagging SNPs of the two genes was conducted using the epistasis option in PLINK to assess potential gene-gene interaction. Genotype data of the C3 tag SNPs were obtained from our previous study [42]. Also, to evaluate the gene-gene interaction between $C 5$ and other candidate genes of AMD and PCV, genotypic data of the SERPING1 [40], C2-CFB-RDBP-SKIV2L [41], CETP [43], ABCG1 [44], PGF [19], ANGPT2 [20], CFH [43] and the HTRA1 [43] genes were extracted from our previous studies for interaction analyses. Moreover, in view of the detection of gene-gender interaction between $C 3$ and gender [42], we also performed SNP-gender interaction analysis for the $C 5$ gene using logistic regression. $P$ value of less than 0.05 was considered statistically significant.

\section{Results}

The age and gender distribution were significantly different between patients and controls (Table 1). They were thus adjusted in the association analyses using logistic regression.

\section{Individual SNP association analysis}

In the International HapMap Project for $\mathrm{CHB}$ population, the 6 selected SNPs captured all alleles in the $C 5$ gene with a minor allele frequency larger than 0.1 and a mean $r^{2}$ of 0.94 . All SNPs were successfully genotyped and conformed to the HWE $(P>0.05)$ in both cases and controls. No significant difference of the allelic frequencies for these SNPs was observed in neovascular AMD and PCV compared with controls $(\mathrm{P}>0.05$, Table 2). None of the SNPs showed a significant association with neovascular AMD or PCV after adjusting for age and gender (all $P$ values $>0.05$ ). Also, no significant association was identified with neovascular AMD and PCV under dominant and recessive models (all $\mathrm{P}$ values > 0.05). Furthermore, none of the SNPs showed significant differences between neovascular AMD and PCV (Table 2).

Table 1 Demographic features of the Study Subjects

\begin{tabular}{|c|c|c|c|c|c|}
\hline & \multirow{2}{*}{$\begin{array}{l}\text { AMD } \\
(n=200)\end{array}$} & \multirow{2}{*}{$\begin{array}{l}\text { PCV } \\
(n=233)\end{array}$} & \multirow{2}{*}{$\begin{array}{l}\text { Control } \\
(n=275)\end{array}$} & \multicolumn{2}{|c|}{ Comparison (P value) } \\
\hline & & & & AMD-Control & PCV-Control \\
\hline Male (\%) & $110(55.0)$ & $162(69.5)$ & $121(44.0)$ & 0.02 & $<0.001$ \\
\hline \multicolumn{6}{|l|}{ Age (years) } \\
\hline Mean \pm SD & $75.3 \pm 7.7$ & $68.5 \pm 9.0$ & $74.3 \pm 7.6$ & 0.16 & $<0.001$ \\
\hline Age range & $50-94$ & $53-90$ & 60-94 & & \\
\hline
\end{tabular}


Table 2 Allelic association of SNPs in C5 with neovascular AMD and PCV

\begin{tabular}{|c|c|c|c|c|c|c|c|c|c|c|c|c|}
\hline \multirow[t]{3}{*}{ SNP } & \multirow[t]{3}{*}{ Location } & \multirow{3}{*}{$\begin{array}{l}\text { Codon } \\
\text { change }\end{array}$} & \multirow{3}{*}{$\begin{array}{l}\text { Minor } \\
\text { allele }\end{array}$} & \multicolumn{3}{|c|}{ Minor allele frequency } & \multicolumn{6}{|c|}{ Allelic association } \\
\hline & & & & \multirow{2}{*}{$\begin{array}{l}\text { AMD } \\
(n=400)\end{array}$} & \multirow{2}{*}{$\begin{array}{l}\text { PCV } \\
(n=466)\end{array}$} & \multirow{2}{*}{$\begin{array}{l}\text { Control } \\
(n=550)\end{array}$} & \multicolumn{2}{|c|}{ AMD-control } & \multicolumn{2}{|c|}{ PCV-control } & \multicolumn{2}{|c|}{ AMD-PCV } \\
\hline & & & & & & & $P$ & OR $(95 \% \mathrm{Cl})$ & $P$ & OR $(95 \% \mathrm{Cl})$ & $\mathrm{P}$ & OR $(95 \% \mathrm{Cl})$ \\
\hline rs1017119 & intron 2 & - & C & 0.16 & 0.15 & 0.14 & 0.54 & $1.12(0.78-1.61)$ & 0.70 & $1.07(0.76-1.52)$ & 0.82 & $0.96(0.66-1.39)$ \\
\hline rs10985126 & exon 11 & G385G & C & 0.24 & 0.23 & 0.24 & 0.83 & $0.97(0.72-1.31)$ & 0.66 & $0.94(0.70-1.25)$ & 0.84 & $0.97(0.71-1.33)$ \\
\hline rs1548782 & intron 18 & - & T & 0.21 & 0.24 & 0.20 & 0.83 & $1.04(0.75-1.42)$ & 0.15 & $1.25(0.93-1.68)$ & 0.26 & $1.20(0.87-1.66)$ \\
\hline rs17611 & exon 19 & V8021 & G & 0.41 & 0.42 & 0.41 & 0.85 & $0.98(0.75-1.27)$ & 0.67 & $1.06(0.82-1.36)$ & 0.57 & $1.08(0.82-1.42)$ \\
\hline rs2269066 & intron 30 & - & $\mathrm{T}$ & 0.20 & 0.19 & 0.22 & 0.44 & $0.88(0.64-1.21)$ & 0.28 & $0.84(0.62-1.15)$ & 0.79 & $0.96(0.68-1.34)$ \\
\hline rs12237774 & exon 34 & A1422A & T & 0.18 & 0.17 & 0.20 & 0.54 & $0.90(0.65-1.26)$ & 0.18 & $0.80(0.58-1.11)$ & 0.50 & $0.89(0.62-1.26)$ \\
\hline
\end{tabular}

$A M D=$ age-related macular degeneration, $C l=$ confidence interval, $O R=$ odds ratio, $P C V=$ polypoidal choroidal vasculopathy, $S N P=$ single nucleotide polymorphism

\section{Linkage disequilibrium (LD) and haplotype analysis}

LD analysis across $C 5$ using these 6 SNPs showed that 2 SNPs, rs17611 and rs1548782 were included in one haplotype block in both neovascular AMD and PCV (Fig. 1). Three haplotypes defined by these two SNPs were identified. None of the haplotypes was significantly associated with neovascular AMD or PCV $(P>0.05$, Table 3), and their distributions between the two disease groups were similar.

\section{Interaction analysis between SNPs in C5 and other genes, and between $\mathrm{C} 5$ and gender}

Genotypic data of major SNPs in the C3 (rs17030) [42], SERPING1 (rs1005510 and rs11603020) [40], C2-CFBRDBP-SKIV2L (rs547154, rs760070, rs429608 and rs453821) [41], CETP (rs3764261) [43], ABCG1 (rs57137919 and rs225396) [44], PGF (rs2268615 and rs2268614) [19], ANGPT2 (rs13255574, rs4455855, rs13269021, and rs11775442) [20], CFH (rs800292) and HTRA1 (rs11200638) [43] genes were extracted from our previous studies for interaction analysis with each of the 6 selected C5 SNPs in this study. However, pairwise epistasis analysis revealed no significant SNP-SNP interaction between $C 5$ and $C 3$ or any other genes for neovascular AMD and PCV (all $P$ values for the interaction term were $>0.05)$. Also, there was no significant SNPgender interaction for $C 5(P>0.1)$.

\section{Discussion}

In this study, we evaluated the associations of 6 haplotype-tagging SNPs in the C5 gene with neovascular AMD and, for the first time, in PCV in a Chinese cohort. Although there are evident involvement of the C5 protein in neovascular AMD as the fragment C5a increased the risk of $\mathrm{CNV}[37,38]$, none of the C5 tagging SNPs or haplotypes showed significant association with neovascular AMD or PCV $(P>0.05)$. In addition, we found no significant SNP-SNP interaction between $C 5$ and $C 3$ or other involved genes in neovascular AMD or PCV.
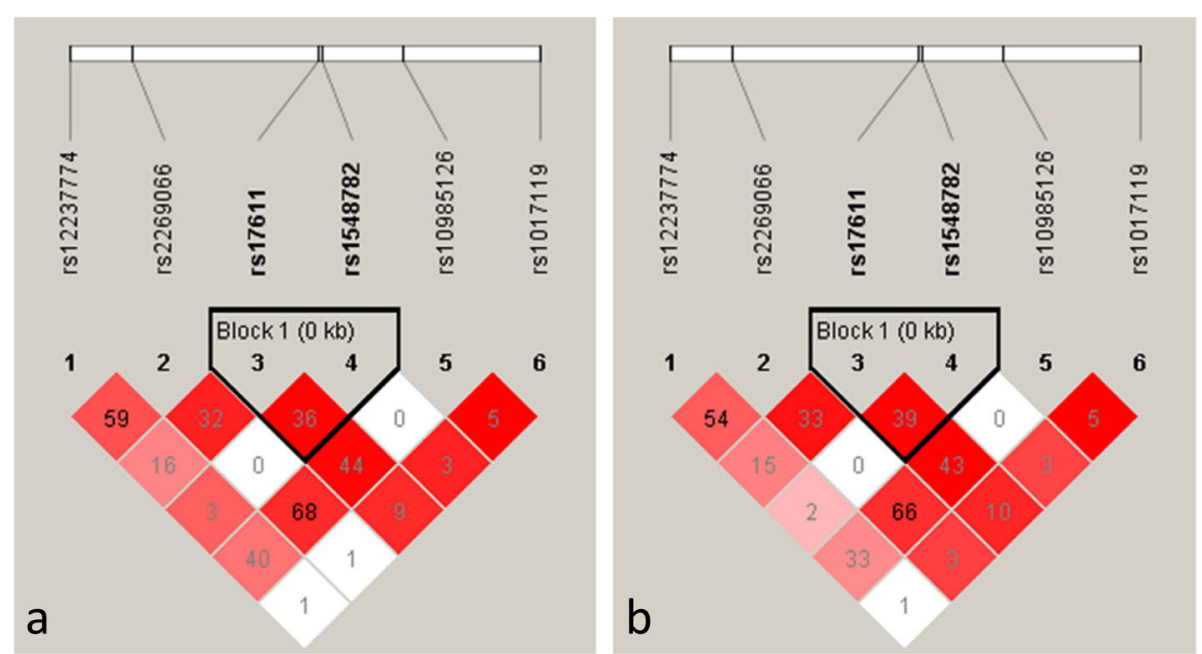

Fig. 1 Linkage disequilibrium (LD) structure of C5 for neovascular AMD (a) and PCV (b). LD was measured using data from all controls and neovascular AMD or PCV in the present study. The confidence interval method was used to define the haplotype blocks. The LD $\left(r^{2}\right)$ between any two SNPs is listed in the cross cells. AMD: age related macular degeneration, PCV: polypoidal choroidal vasculopathy, SNPs: single nucleotide polymorphisms 
Table 3 Haplotype associations of C5 with neovascular AMD and PCV

\begin{tabular}{|c|c|c|c|c|c|c|}
\hline \multirow{2}{*}{$\begin{array}{l}\text { Haplotype } \\
\text { rs17611-rs1548782 }\end{array}$} & \multicolumn{3}{|l|}{ Frequency } & \multicolumn{3}{|l|}{ Association (P) } \\
\hline & AMD & PCV & Control & AMD-Control & PCV-Control & AMD-PCV \\
\hline $1 \mathrm{~A}-\mathrm{A}$ & $237.9(0.59)$ & $268.1(0.58)$ & $322.8(0.59)$ & 0.81 & 0.71 & 0.85 \\
\hline $2 \mathrm{G}-\mathrm{T}$ & $83.9(0.21)$ & $112.9(0.24)$ & $110.8(0.20)$ & 0.76 & 0.12 & 0.17 \\
\hline $3 \mathrm{G}-\mathrm{A}$ & $78.1(0.20)$ & $84.9(0.18)$ & $115.2(0.21)$ & 0.59 & 0.28 & 0.36 \\
\hline
\end{tabular}

$A M D=$ age related macular degeneration, $P C V=$ polypoidal choroidal vasculopathy

Our results are consistent with those in previous studies on AMD patients of non-Chinese ethnicity. Yates et al. reported no association between C5 SNPs and advanced AMD, including geography atrophy and neovascular AMD, in a Caucasian population of 603 cases and 350 controls [30]. A subsequent study showed that the tagging SNPs across C5 were not associated with advanced AMD in an European population of 1238 cases and 934 controls [31]. Later, Baas et al. performed a comprehensive analysis between C5 SNPs and several forms of AMD, including early AMD, geography atrophy and neovascular AMD, in four independent studies [39]. Although significant association between $C 5$ and AMD was identified in the original study on a Dutch population (AMRO-NL study), this association could not be replicated in the other three study cohorts from the Netherlands, the United Kingdom, and the United States [39]. The incidence of neovascular AMD was higher in the AMRO-NL cohort (50.4\%), as compared with that of the other three cohorts $(5.8,43.1$ and $42.8 \%$, respectively) [39], which might have contributed to the different results. Here we made the first attempt to investigate $C 5$ in PCV. We did not find significant associations between individual C5 SNPs and PCV or neovascular AMD. Our results thus rule out a definite role of $C 5$ in neovascular AMD and PCV, although further confirmation in larger study cohorts should be warranted.

AMD and PCV are multifactorial late-onset diseases with genetic susceptibility, environmental factors being the major risk factors. Gene-gene interactions of $\mathrm{CFH}$ and $A R M S 2$, and interaction between genes and environmental risk factors, such as smoking and gender, have been found to be implicated in the disease risk of AMD and PCV [42, 45-48]. There was also evidence to suggest the existence of epistasis in AMD [49]. Although the exact mechanism for the epistasis was unclear, a combination of two SNPs, rs1394608 in SGCD and rs3743175 in SCAPER, was identified to be associated with AMD in the analysis of a genome-wide casecontrol data set [49]. Since C5 and C3 interact with each other biologically in the complement system, we evaluated the role of epistasis between C5 SNPs and C3 SNPs. However, we identified no significant SNP-SNP interaction for neovascular AMD and PCV between the tagging SNPs in C5 and C3. Also, no gene-gene interaction was identified between $C 5$ and C2-CFB-RDBP-SKIV2L, SERPING1, CETP, ABCG1, PGF, ANGPT2, CFH or HTRA1. Moreover, no gene-gender interaction was identified for $C 5$ in AMD or PCV.

This study provides an evaluation of the $C 5$ gene and interaction between $C 5$ and $C 3$ and other candidate genes in neovascular AMD and PCV in a Chinese cohort. However, several limitations should be taken into account when interpreting the negative findings. First, the sample size in each group was relatively small. Our samples provided a statistical power of approximately $50 \%$ to rule out the null hypothesis of no association at the alpha level of 0.05 , assuming a modest odds ratio of 1.5. Therefore, larger study cohorts are needed to confirm the lack of association between $C 5$ and neovascular AMD or PCV in Chinese. Second, the mean age and gender ratios were significantly different between the case and control groups, especially between PCV and controls. Therefore, further work should include more age-matched female patients and male controls so that there would be age and gender balance in both patients and controls. Third, the smoking status and clinical parameters of some study subjects were not available, therefore these factors could not be incorporated in the data analysis of this study. New recruitment work is ongoing to resolve these issues.

\section{Conclusions}

This study suggests that the C5 SNPs did not have a significant association with the disease risk of neovascular AMD and PCV in the Hong Kong Chinese cohort. In addition, no significant epistasis was identified between $C 5$ and gender or SNPs in other genes, including $C 2$ CFB-RDBP-SKIV2L, C3, SERPING1, CETP, ABCG1, $P G F, A N G P T 2, C F H$ or HTRA1. In view of the limited sample size in this study, further studies in large samples from different populations are warranted to confirm the role of the $C 5$ gene in the genetic susceptibility of neovascular AMD and PCV.

\section{Acknowledgements \\ The authors thank all the participants in this study.}

\section{Authors' contributions}

$\mathrm{KL}, \mathrm{CPP}$ and $\mathrm{LJC}$ conceived the idea and designed the study. $\mathrm{KL}$ and $\mathrm{LM}$ performed the experiments and analyzed the data. TYYL, MEB, CCT and LC recruited the study subjects. POST provided technical support. $\mathrm{KL}$ interpreted 
the data and drafted the manuscript. CPP and LC critically revised the manuscript. CCT, CPP and LC provided research funding. All authors read and approved the final manuscript.

\section{Funding}

This study was supported in part by the General Research Fund, Hong Kong (14120516 [LCC]), the Direct Grant of Chinese University of Hong Kong Medical Panel, Hong Kong (4054281 [LJC]), and the Endowment Fund for Lim Por-Yen Eye Genetics Research Centre, Hong Kong.

\section{Availability of data and materials}

Datasets related to this study will be available from the corresponding author upon request.

\section{Ethics approval and consent to participate}

The study protocol was approved by the Ethics Committee on Human Research, the Chinese University of Hong Kong (Approval No:: CREC Ref:: 2014.211). The study procedures followed the tenets of the Declaration of Helsinki. All study subjects provided written informed consent after the explanation of the study nature.

\section{Consent for publication}

All study subjects gave their informed consent. This manuscript does not contain any individual person's data in any form.

\section{Competing interests}

The authors declare that they have no competing interests.

\section{Received: 31 May 2019 Accepted: 17 October 2019} Published online: 07 November 2019

\section{References}

1. Maruko I, lida T, Saito M, Nagayama D, Saito K. Clinical characteristics of exudative age-related macular degeneration in Japanese patients. Am J Ophthalmol. 2007:144(1):15-22.

2. Kawasaki R, Yasuda M, Song SJ, Chen SJ, Jonas JB, Wang JJ, et al. The prevalence of age-related macular degeneration in Asians: a systematic review and meta-analysis. Ophthalmology. 2010;117(5):921-7.

3. Liu X, Zhao P, Tang S, Lu F, Hu J, Lei C, et al. Association study of complement factor $\mathrm{H}, \mathrm{C2}, \mathrm{CFB}$, and C3 and age-related macular degeneration in a Han Chinese population. Retina. 2010;30(8):1177-84.

4. Warrow DJ, Hoang QV, Freund KB. Pachychoroid pigment epitheliopathy. Retina. 2013;33(8):1659-72.

5. Cheung CMG, Lai TYY, Ruamviboonsuk P, Chen SJ, Chen Y, Freund KB, et al. Polypoidal choroidal vasculopathy: definition, pathogenesis, diagnosis, and management. Ophthalmology. 2018;125(5):708-24.

6. Yannuzzi LA, Wong DW, Sforzolini BS, Goldbaum M, Tang KC, Spaide RF, et al. Polypoidal choroidal vasculopathy and neovascularized age-related macular degeneration. Arch Ophthalmol. 1999;117(11):1503-10.

7. Terasaki H, Ishikawa K, Suzuki T, Nakamura M, Miyake K, Miyake Y. Morphologic and angiographic assessment of the macula after macular translocation surgery with 360 degrees retinotomy. Ophthalmology. 2003; 110(12):2403-8.

8. Moorthy RS, Lyon AT, Rabb MF, Spaide RF, Yannuzzi LA, Jampol LM. Idiopathic polypoidal choroidal vasculopathy of the macula. Ophthalmology. 1998;105(8):1380-5.

9. Gomi F, Ohji M, Sayanagi K, Sawa M, Sakaguchi H, Oshima Y, et al. One-year outcomes of photodynamic therapy in age-related macular degeneration and polypoidal choroidal vasculopathy in Japanese patients. Ophthalmology. 2008;115(1):141-6.

10. Gomi F, Sawa M, Sakaguchi H, Tsujikawa M, Oshima Y, Kamei M, et al. Efficacy of intravitreal bevacizumab for polypoidal choroidal vasculopathy. Br J Ophthalmol. 2008;92(1):70-3.

11. Liu Y, Wen F, Huang S, Luo G, Yan H, Sun Z, et al. Subtype lesions of neovascular age-related macular degeneration in Chinese patients. Graefes Arch Clin Exp Ophthalmol. 2007:245(10):1441-5.

12. Byeon SH, Lee SC, Oh HS, Kim SS, Koh HJ, Kwon OW. Incidence and clinical patterns of polypoidal choroidal vasculopathy in Korean patients. Jpn J Ophthalmol. 2008;52(1):57-62.
13. Laude A, Cackett PD, Vithana EN, Yeo IY, Wong D, Koh AH, et al. Polypoidal choroidal vasculopathy and neovascular age-related macular degeneration: same or different disease? Prog Retin Eye Res. 2010;29(1):19-29.

14. Lorentzen TD, Subhi Y, Sørensen TL. Prevalence of polypoidal choroidal vasculopathy in white patients with exudative age-related macular degeneration: systematic review and meta-analysis. Retina. 2018;38(12): 2363-71.

15. Subhi Y, Krogh Nielsen M, Molbech CR, Oishi A, Singh A, Nissen MH, et al. Plasma markers of chronic low-grade inflammation in polypoidal choroidal vasculopathy and neovascular age-related macular degeneration. Acta Ophthalmol. 2019;97(1):99-106.

16. Dewan A, Liu M, Hartman S, Zhang SS, Liu DT, Zhao C, et al. HTRA1 promoter polymorphism in wet age-related macular degeneration. Science. 2006;314(5801):989-92.

17. Klein RJ, Zeiss C, Chew EY, Tsai JY, Sackler RS, Haynes C, et al. Complement factor $\mathrm{H}$ polymorphism in age-related macular degeneration. Science. 2005; 308(5720):385-9.

18. Fritsche LG, Ig | W, Bailey JN, Grassmann F, Sengupta S, Bragg-Gresham JL, et al. A large genome-wide association study of age-related macular degeneration highlights contributions of rare and common variants. Nat Genet. 2016;48(2):134-43.

19. Chen LJ, Ma L, Chu WK, Lai TY, Chen H, Brelén ME, et al. Identification of PGF as a new gene for neovascular age-related macular degeneration in a Chinese population. Invest Ophthalmol Vis Sci. 2016;57(4):1714-20.

20. Ma L, Brelen ME, Tsujikawa M, Chen H, Chu WK, Lai TY, et al. Identification of ANGPT2 as a new gene for neovascular age-related macular degeneration and polypoidal choroidal vasculopathy in the Chinese and Japanese populations. Invest Ophthalmol Vis Sci. 2017;58(2):1076-83.

21. Cheng CY, Yamashiro K, Chen LJ, Ahn J, Huang L, Huang L, et al. New loci and coding variants confer risk for age-related macular degeneration in east Asians. Nat Commun. 2015;6:6063.

22. Huang LZ, Li YJ, Xie XF, Zhang JJ, Cheng CY, Yamashiro $K$, et al. Wholeexome sequencing implicates UBE3D in age-related macular degeneration in east Asian populations. Nat Commun. 2015:6:6687.

23. Ng TK, Chen L, Liu DT, Tam PO, Chan WM, Liu K, et al. Multiple gene polymorphisms in the complement factor $\mathrm{H}$ gene are associated with exudative age-related macular degeneration in Chinese. Invest Ophthalmol Vis Sci. 2008:49(8):3312-7.

24. Tam PO, Ng TK, Liu DT, Chan WM, Chiang SW, Chen LJ, et al. HTRA1 variants in exudative age-related macular degeneration and interactions with smoking and CFH. Invest Ophthalmol Vis Sci. 2008;49(6):2357-65.

25. Ma L, Li Z, Liu K, Rong SS, Brelen ME, Young AL, et al. Association of genetic variants with polypoidal choroidal vasculopathy: a systematic review and updated meta-analysis. Ophthalmology. 2015;122(9):1854-65.

26. Huang $L$, Zhang $H$, Cheng $C Y$, Wen F, Tam PO, Zhao $P$, et al. A missense variant in FGD6 confers increased risk of polypoidal choroidal vasculopathy. Nat Genet. 2016:48(6):640-7.

27. Desmettre TJ. Epigenetics in age-related macular degeneration (AMD). J Fr Ophtalmol. 2018:41(9):e407-15.

28. Gemenetzi M, Lotery AJ. The role of epigenetics in age-related macular degeneration. Eye (Lond). 2014;28(12):1407-17.

29. Gold B, Merriam JE, Zernant J, Hancox LS, Taiber AJ, Gehrs K, et al. Variation in factor B (BF) and complement component 2 (C2) genes is associated with age-related macular degeneration. Nat Genet. 2006;38(4):458-62.

30. Yates JR, Sepp T, Matharu BK, Khan JC, Thurlby DA, Shahid H, et al. Complement C3 variant and the risk of age-related macular degeneration. N Engl J Med. 2007;357(6):553-61.

31. Maller JB, Fagerness JA, Reynolds RC, Neale BM, Daly MJ, Seddon JM. Variation in complement factor 3 is associated with risk of age-related macular degeneration. Nat Genet. 2007;39(10):1200-1.

32. Fagerness JA, Maller JB, Neale BM, Reynolds RC, Daly MJ, Seddon JM. Variation near complement factor I is associated with risk of advanced AMD. Eur J Hum Genet. 2009;17(1):100-4

33. Johnson LV, Ozaki S, Staples MK, Erickson PA, Anderson DH. A potential role for immune complex pathogenesis in drusen formation. Exp Eye Res. 2000; 70(4):441-9.

34. Anderson DH, Mullins RF, Hageman GS, Johnson LV. A role for local inflammation in the formation of drusen in the aging eye. Am J Ophthalmol. 2002;134(3):411-31.

35. Reynolds R, Hartnett ME, Atkinson JP, Giclas PC, Rosner B, Seddon JM. Plasma complement components and activation fragments: associations 
with age-related macular degeneration genotypes and phenotypes. Invest Ophthalmol Vis Sci. 2009;50(12):5818-27.

36. Scholl HP, Charbel Issa P, Walier M, Janzer S, Pollok-Kopp B, Borncke F, et al. Systemic complement activation in age-related macular degeneration. PLoS One. 2008;3(7):e2593.

37. Nozaki M, Raisler BJ, Sakurai E, Sarma JV, Barnum SR, Lambris JD, et al. Drusen complement components C3a and C5a promote choroidal neovascularization. Proc Natl Acad Sci U S A. 2006;103(7):2328-33.

38. Cortright DN, Meade R, Waters SM, Chenard BL, Krause JE. C5a, but not C3a, increases VEGF secretion in ARPE-19 human retinal pigment epithelial cells. Curr Eye Res. 2009;34(1):57-61.

39. Baas DC, Ho L, Ennis S, Merriam JE, Tanck MW, Uitterlinden AG, et al. The complement component 5 gene and age-related macular degeneration. Ophthalmology. 2010;117(3):500-11.

40. Liu K, Lai TY, Ma L, Lai FH, Young AL, Brelen ME, et al. Ethnic differences in the association of SERPING1 with age-related macular degeneration and polypoidal choroidal vasculopathy. Sci Rep. 2015;5:9424.

41. Liu K, Chen LJ, Tam PO, Shi Y, Lai TY, Liu DT, et al. Associations of the C2CFB-RDBP-SKIV2L locus with age-related macular degeneration and polypoidal choroidal vasculopathy. Ophthalmology. 2013;120(4):837-43.

42. Liu K, Lai TY, Chiang SW, Chan VC, Young AL, Tam PO, et al. Gender specific association of a complement component 3 polymorphism with polypoidal choroidal vasculopathy. Sci Rep. 2014;4:7018.

43. Liu K, Chen LJ, Lai TY, Tam PO, Ho M, Chiang SW, et al. Genes in the highdensity lipoprotein metabolic pathway in age-related macular degeneration and polypoidal choroidal vasculopathy. Ophthalmology. 2014;121(4):911-6.

44. Ma L, Liu K, Tsujikawa M, Chen H, Brelen ME, Chan VC, et al. Association of ABCG1 with neovascular age-related macular degeneration and polypoidal choroidal vasculopathy in Chinese and Japanese. Invest Ophthalmol Vis Sci. 2016;57(13):5758-63.

45. Nakanishi H, Yamashiro K, Yamada R, Gotoh N, Hayashi H, Nakata I, et al. Joint effect of cigarette smoking and CFH and LOC387715/HTRA1 polymorphisms on polypoidal choroidal vasculopathy. Invest Ophthalmol Vis Sci. 2010;51(12):6183-7.

46. Lee SJ, Kim NR, Chin HS. LOC387715/HTRA1 polymorphisms, smoking and combined effects on exudative age-related macular degeneration in a Korean population. Clin Exp Ophthalmol. 2010:38(7):698-704.

47. Seitsonen SP, Onkamo P, Peng G, Xiong M, Tommila PV, Ranta PH, et al. Multifactor effects and evidence of potential interaction between complement factor $\mathrm{H}$ Y402H and LOC387715 A69S in age-related macular degeneration. PLoS One. 2008;3(12):e3833.

48. Kim YH, Kim HS, Mok JW, Joo CK. Gene-gene interactions of CFH and LOC387715/ARMS2 with Korean exudative age-related macular degeneration patients. Ophthalmic Genet. 2013;34(3):151-9.

49. Tang W, Wu X, Jiang R, Li Y. Epistatic module detection for case-control studies: a Bayesian model with a Gibbs sampling strategy. PLoS Genet. 2009;5(5):e1000464.

Ready to submit your research? Choose BMC and benefit from:

- fast, convenient online submission

- thorough peer review by experienced researchers in your field

- rapid publication on acceptance

- support for research data, including large and complex data types

- gold Open Access which fosters wider collaboration and increased citations

- maximum visibility for your research: over $100 \mathrm{M}$ website views per year

At $\mathrm{BMC}$, research is always in progress.

Learn more biomedcentral.com/submissions 